\title{
Experimental study on the attenuation of pressure waves in a cavity induced by flow boiling
}

\author{
J. Rojas-Herrera ${ }^{a}$, A. Velazquez ${ }^{\text {b }}$, J.R. Arias ${ }^{\text {b }}$, A. Barrero ${ }^{\text {b }}$ \\ ${ }^{a}$ Department of Mechanical Engineering, Massachusetts Institute of Technology, 77 Massachusetts Avenue, Cambridge, MA 02139, USA \\ ${ }^{\mathrm{b}}$ Aerospace Propulsion and Fluid Mechanics Department, School of Aeronautics, Universidad Politecnica de Madrid, Plaza del Cardenal Cisneros 3, 28040 Madrid, Spain
}

\begin{abstract}
A B S T R A C T
The experimental work presented in this article deals with the study of low-frequency high-amplitude pressure wave attenuation in a cavity when boiling takes place on the inside. The working fluid was HFE7100. Regarding the flow regime, the study considered two different situations: pool boiling and flow boiling in the low to moderate Reynolds number regime. Regarding the operating parameters, the study considered: (a) the type of evaporator, (b) the temperature of the evaporator, and (c) the frequency of the pressure waves. Three different types of evaporators were manufactured and tested: a flat one and another two based on a micro pin fin structure. Pin fin sizes for these two evaporators were $500 \mu \mathrm{m} \times 500 \mu \mathrm{m} \times 500 \mu \mathrm{m}$ and $1000 \mu \mathrm{m} \times 1000 \mu \mathrm{m} \times 1000 \mu \mathrm{m}$ respectively. The temperature of the evaporators was varied between $40^{\circ} \mathrm{C}$ and $80^{\circ} \mathrm{C}$. Frequency of the pressure waves changed between $35 \mathrm{~Hz}$ and $75 \mathrm{~Hz}$. An additional isothermal reference case (no boiling) was used for comparison purposes. The typical order of magnitude of the peak-to-peak applied pressure amplitudes was 0.2 bar. Regarding the results, it was found that boiling causes a significant attenuation of the peak-to-peak amplitude of the pressure waves in the cavity. The main parameter acting on this attenuation was the temperature of the evaporator (related to the input electrical power), while the actual micro-structure of the evaporator played a nearly negligible role. Also, it was found that while a small electrical power input of about $5 \mathrm{~W}$ achieves an attenuation factor of about 0.5 , four times as much power $(20 \mathrm{~W})$ is needed to halve again the attenuation factor to 0.25 . This suggests a scaling law relating attenuation and power which could be used for engineering design purposes.
\end{abstract}

\section{Introduction}

The interaction of pressure waves and bubbly flow is a subject that has been studied for a long time. In fact, one of the earliest studies on the subject was published by Mallock [1] more than a century ago. Other theoretical studies related to modelization of this phenomenon have been published by Carstensen and Foldy [2], Wijngaarden [3], Caflisch et al. [4], and Commander and Prosperetti [5] that, in addition, performed a systematic comparison between theoretical models and experimental results. On the side of practical applications, the interaction of pressure waves and bubbly flows has been directed, mainly, to the problems of sound propagation/attenuation and heat transfer enhancement. More recently, micro-bubble injection has been proposed as a mean to mitigate damage caused by strong pressure waves in some types of nuclear technologies.
Regarding sound propagation and attenuation in bubbly flows, it is relevant to mention the works of Silberman [6], Prosperetti [7], D'Agostino and Brennen [8] and Nomura and Nakagawa [9]. In these references, the authors studied the interaction between sound and ultrasound fields and bubble flows using different means to gather both qualitative and quantitative information propagation and attenuation characteristics. A similar study using pressure waves of moderate amplitude instead has been reported by Dontsov and Nakoryakov [10]. In this study, average bubble diameter was $0.5 \mathrm{~mm}$ and pressure increments were of the order of $0.1 \mathrm{MPa}$. Typical pressure attenuations were of the order of 0.1 and it was found that non-uniform bubble distribution enhanced this attenuation. Strong pressure oscillations of the order of $50 \%$ of the ambient pressure past a bubbly flow have been studied numerically by Raju et al. [11] although, in this case, the focus was more on the development and validation of a hybrid Lagrangian-Eulerian flow solver than on the specific physics aspects of the problem itself. Regarding applications for heat transfer enhancement, the use of ultra sound fields was proposed long time ago, 


\author{
Nomenclature \\ $f \quad$ frequency $(\mathrm{Hz})$ \\ $P \quad$ pressure (bar) \\ Qlow volume flow rate $\left(\mathrm{cm}^{3} / \mathrm{min}\right)$ \\ Re Reynolds number \\ $T$ temperature $\left({ }^{\circ} \mathrm{C}\right)$ \\ $T_{\text {evaporator }}$ evaporator surface temperature $\left({ }^{\circ} \mathrm{C}\right)$ \\ $t \quad$ time (s)
}

$K_{\text {APcavity }}$ pressure attenuation factor in the cavity

$\Delta P \quad$ peak-to-peak pressure amplitude (bar)

$\Delta P_{\text {cavity }}$ peak-to-peak pressure amplitude in the cavity (bar)

$\Delta P_{\text {reference }}$ peak-to-peak reference pressure amplitude (bar)
Fand [12] and Lee and Parker [13]. The specific influence of ultra sound fields on boiling has been reported, among others, by Park and Bergles [14], Iida and Tsutsui [15], Yamashiro et al. [16], Kim et al. [17] and Baffigi and Bartoli [18]. In the last case, that is the most recent, Baffigi and Bartoli [18] used $40 \mathrm{kHz}$ ultra sonic waves and reported increases on the heat transfer coefficient of the order of $18-25 \%$. Finally, it is important to mention the work of Futakawa et al. [19] which have proposed bubbly flow as a mitigation methodology for the erosion caused by strong pressure waves in a highpower pulsed spallation neutron facility. In their experimental work, the authors injected helium micro bubbles (average diameter $100 \mu \mathrm{m}$ ) into flowing mercury. Then, a low frequency $(1 \mathrm{~Hz})$ high amplitude (0.4 MPa) pressure wave was applied to the flow and its time evolution was measured and analyzed for a variety of different conditions. In their conclusions, the authors stated the potential of this technology for damage mitigation purposes and suggested a further approach to control it by acting on the spatial distribution of bubbles.

The work described in this article deals with an experimental study aiming to characterize low-frequency high-amplitude pressure wave attenuation in a fluid inside a cavity using heat transfer to a flat/micro-pin fin evaporator as the control parameter. The heat transfer causes the flow to boil and a continuous supply of bubbles is generated at the evaporator that interacts with the pressure waves. The study was performed under both pool boiling and flow boiling conditions, and scaling laws relating pressure wave mitigation to thermal power were generated. Regarding the organization of the article, the problem and the experimental setup are described first; then, results are presented and discussed and, finally, conclusions are given.

\section{Description of the problem and experimental setup}

The problem considered was that of low-frequency high-amplitude pressure wave attenuation inside a cavity in which boiling took place under controlled conditions. The cloud of bubbles generated at the evaporator modified the overall character of the carrier fluid from purely incompressible to semi-compressible and this fact changed wave behavior significantly. Different types of evaporators and different levels of supplied heat per unit time (power) were considered. The working fluid was HFE7100 and the experiments were performed under both pool and flow boiling conditions. Specifically, pressure attenuation in the cavity and in the inlet channel was measured as a function of the governing parameters of the problem.

To carry out the study, a dedicated experimental facility was designed, manufactured and assembled. The facility had primary and a secondary circuits, see Fig. 1 (flow motion is clockwise). The primary circuit contained: (a) a pulsating (reciprocating) pump controlled via a frequency variator, (b) the cavity where boiling took place, and (c) a reservoir. A flow meter was inserted in the line connecting the cavity to the reservoir. A junction was placed in the line connecting the pump to the cavity. The line issuing from this junction (the secondary circuit) ended up in the reservoir. This line had an insert with a valve, so acting on this valve allowed the flow to be diverted from the primary to the secondary circuits and vice versa. The practical effect was that the flow rate entering the cavity could be controlled. In the case of pool boiling, only a very small amount of fluid per unit time was allowed to enter the cavity to compensate for the fluid that was evaporating. The cavity was transparent to allow monitoring of the liquid surface level. In the case of flow boiling, different flow rates were allowed to enter the cavity which meant that different flow Reynolds numbers were considered. Since properties of the working fluid HFE7100 are temperature dependent, the reservoir was kept refrigerated so that the fluid temperature was constant in the line going from the reservoir to the pump. The cavity was instrumented with five thermocouples (TC1 to TC5 in Fig. 1) that measured fluid temperature, evaporator temperature, and external temperature of the cavity itself (needed to evaluate heat losses associated to natural convection). Another thermocouple was located inside the reservoir (TC7) and yet another one (TC6) in the line leading to the cavity. In addition to the continuous reading of the thermocouples, a contact surface Amprobe TPP2C thermometer was also used throughout the experiments to cross-check the temperature measurement of the external walls of the cavity and to ensure that no hot spots were present. Regarding pressure measurements, one pressure sensor was inserted in the cavity (PS in Fig. 1) and another one (PS) in the line leading to it (and after the junction that separated the primary and secondary circuits).

The cavity was manufactured out of methacrylate. Its dimensions (in $\mathrm{mm}$ ) and front view are shown in Fig. 2. Depth of the cavity was $20 \mathrm{~mm}$. Wall thickness was $15 \mathrm{~mm}$. When full, it contained $46 \mathrm{~cm}^{3}$ of HFE7100. Internal diameters of inlet and outlet lines were $4 \mathrm{~mm}$ and $12 \mathrm{~mm}$ respectively.

Three different evaporators were manufactured and tested in the cavity. Overall dimensions of the square-shaped evaporators, manufactured on Aluminum alloy, were $1 \mathrm{~cm} \times 1 \mathrm{~cm}$. The first evaporator was flat. The second one contained an array of 25 pin fins of cubic shape and individual size of $1000 \mu \mathrm{m} \times 1000 \mu \mathrm{m} \times 1000 \mu \mathrm{m}$.

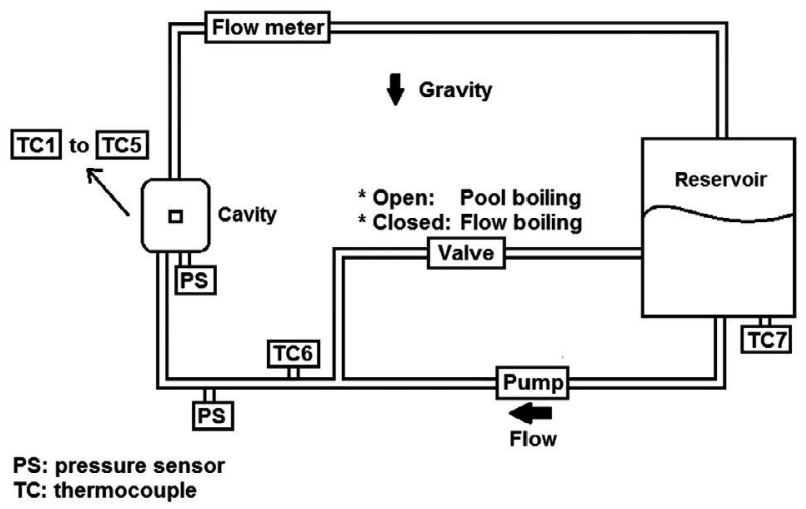

Fig. 1. Sketch of the experimental facility. 


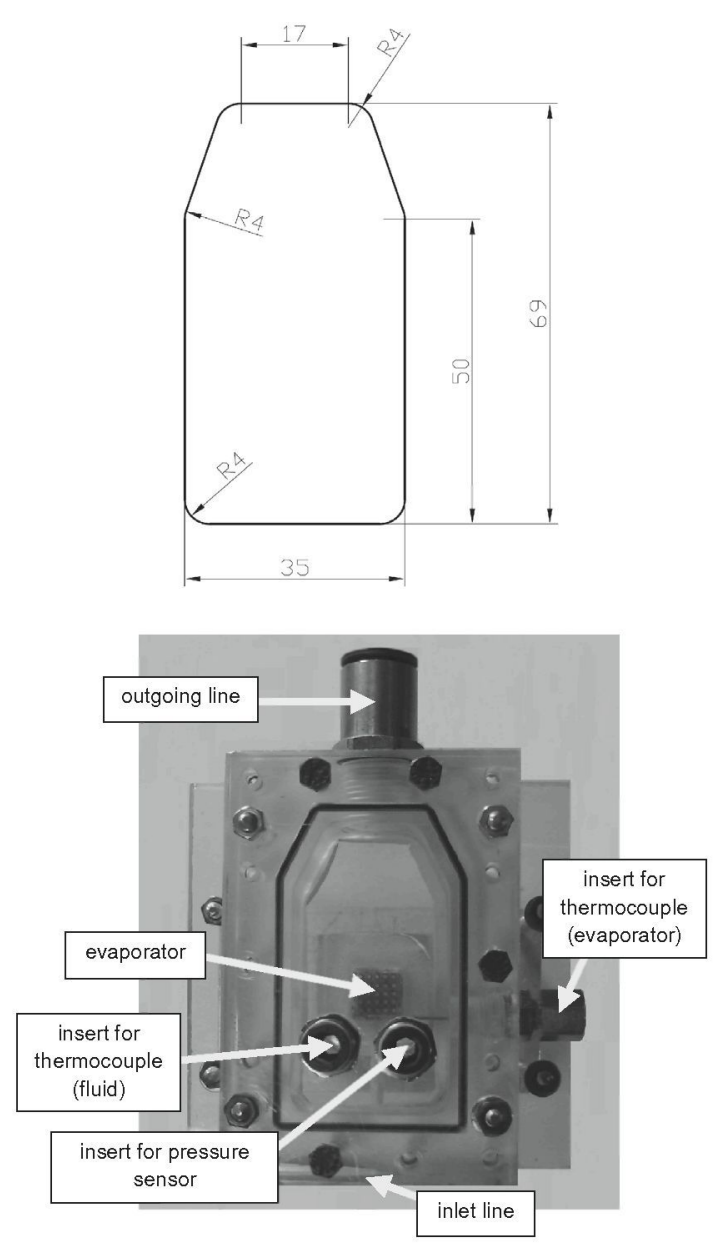

Fig. 2. Front view of the cavity and its dimensions in $\mathrm{mm}$.

Separation between pin fins was also $1000 \mu \mathrm{m}$. The third evaporator contained an array of 100 pin fins of cubic shape and individual size of $500 \mu \mathrm{m} \times 500 \mu \mathrm{m} \times 500 \mu \mathrm{m}$. Separation between pin fins was also $500 \mu \mathrm{m}$. A picture of this third evaporator is shown in Fig. 3 . Each evaporator was manufactured in one of the faces of a single block of Aluminum alloy having parallelepiped shape. The block itself was hollowed out to allow for a cartridge electrical resistance to be inserted, see Fig. 4. This compactness and the high thermal conductivity of the Aluminum alloy $(180 \mathrm{~W} / \mathrm{m} \mathrm{K})$ led to a high spatial uniformity of the temperature field in the block (that was

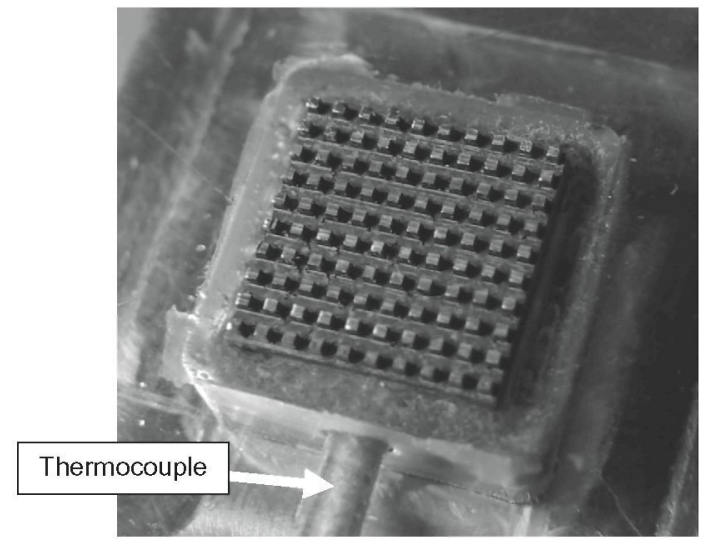

Fig. 3. Picture of the evaporator with cubic pin fins of $500 \mu \mathrm{m} \times 500 \mu \mathrm{m} \times 500 \mu \mathrm{m}$. The cylindrical shape seen at the bottom of the picture is the thermocouple inserted under the evaporator surface to measure its temperature.

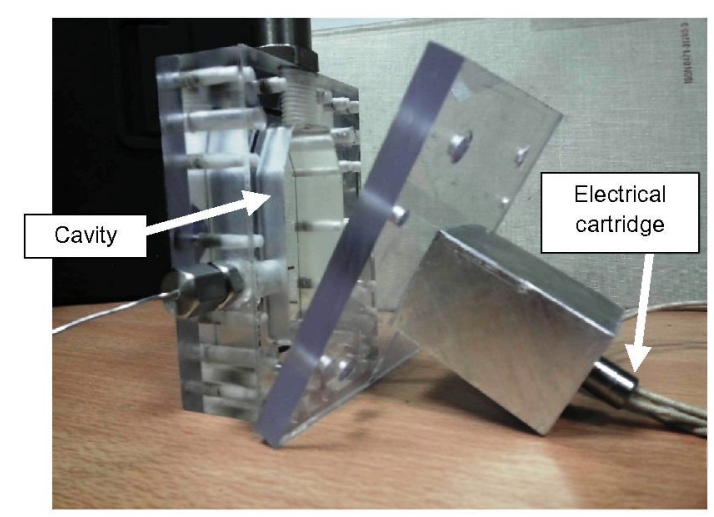

Fig. 4. The cavity, block and electrical cartridge seen on their side.

further thermally isolated with Styrofoam layers). The thermal uniformity was verified using a contact surface thermometer and with the thermocouple inserted under the evaporator surface. A global picture of the experimental test bench is presented in Fig. 5.

The reciprocating pump was a Gotec ETS $150-\mathrm{P} / \mathrm{C}$. It had two internal pistons that alternated fluid admission and impulsion (the pressure wave). The frequency variator was a Delta VFD007L21B and it allowed for a continuous variation of frequency in the range of $1-400 \mathrm{~Hz}$. The flow meter was a hall effect turbine type Gems FT-210 and it measured in the range from $100 \mathrm{~cm}^{3} / \mathrm{min}$ to $2500 \mathrm{~cm}^{3} / \mathrm{min}$ with an uncertainty of $\pm 3 \%$. Some of the flow boiling results, specifically those performed at the higher frequencies, involved flow rates of about $50 \mathrm{~cm}^{3} / \mathrm{min}$ (smaller than the lower threshold recommended by the flow meter manufacturer). Therefore, the flow meter had to be re-calibrated for these cases. The re-calibration was performed using a series of calibrated test tubes and it was found that measurement uncertainty in these low flow rate conditions was $\pm 10 \%$. Pressure sensors were Ellison Sensors Inc. (ESI-GS4101). They measured with an uncertainty of $\pm 0.5 \%$. Thermocouples were TC-SA T-type. Uncertainty was $\pm 0.5^{\circ} \mathrm{C}$. When the order to the manufacturer was filed, it was specified that the whole set of thermocouples should belong to the same manufacturing batch, so the actual measurement uncertainty, whatever it was, was the same for all units. A $50 \mathrm{~W}$ cartridge Joule heater was used to set the evaporator to the desired temperature. Because of the continuous heat loss to the fluid, the electrical input had to be controlled. To this end, a National Instruments Compact RIO N19201 controller was used. The working fluid was HFE 7100 . In the range from $20^{\circ} \mathrm{C}$ to $65^{\circ} \mathrm{C}$ its density and dynamic viscosity changed from

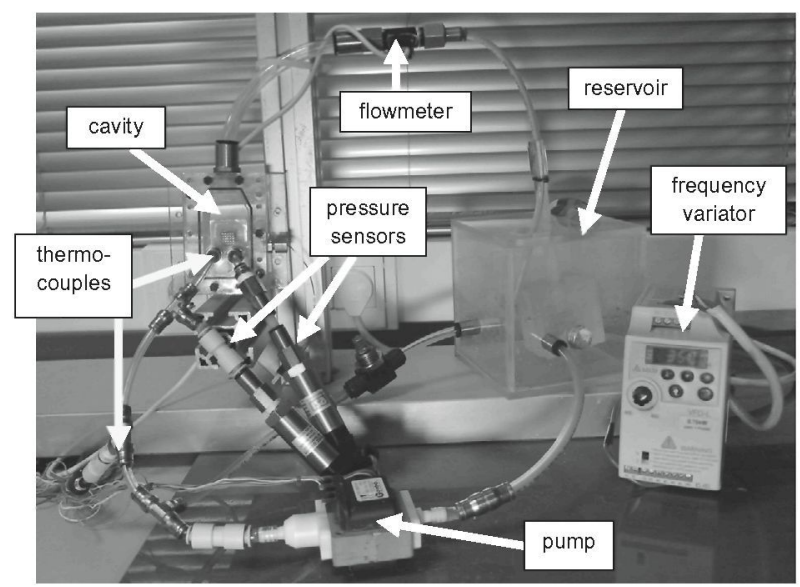

Fig. 5. Picture of the experimental setup. 
$1482 \mathrm{~kg} / \mathrm{m}^{3}$ and $5.83 \times 10^{-4} \mathrm{~kg} / \mathrm{ms}$ to $1353 \mathrm{~kg} / \mathrm{m}^{3}$ and $3.50 \times 10^{-4} \mathrm{~kg} / \mathrm{ms}$ respectively. The boiling temperature at $1 \mathrm{bar}$ was $60^{\circ} \mathrm{C}$. A description of its main physical properties and a comparison with the properties of similar working fluids are provided in Ref. [20]. The full description of its properties could be found in [21]. The tests were also video recorded using a highspeed high-precision Casio Exilim Pro EX-F1 camera.

\section{Pool boiling results}

\subsection{Isothermal reference case}

First of all, a reference case was defined to allow for a meaningful comparison with actual pool boiling tests. In this reference case no heat was applied to the evaporator so the test was isothermal and the working fluid was at room temperature conditions. Pressure waves at $35 \mathrm{~Hz}, 45 \mathrm{~Hz}, 55 \mathrm{~Hz}, 65 \mathrm{~Hz}$ and $75 \mathrm{~Hz}$ were generated at the pump and the time history of pressure evolution was recorded inside the cavity and in the line leading to the cavity. In this case, the entre fluid flow was diverted to the secondary circuit so no net flow entered the cavity; only pressure waves traveled into the cavity and acted upon the standing fluid. It is to be noted that the peak to peak amplitude of the pressure waves and their frequency could not be controlled independently. The reason is that in the unsteady Poiseuille regime (that is representative of the flow regime actually taking place on the experiment) pressure amplitude and frequency and mass flow rate are coupled in the flow solution so a given frequency leads to a single pressure wave amplitude [22]. The time history of pressure waves in the cavity (with the $500 \mu \mathrm{m}$ pin fin evaporator) and in the inlet line when a frequency of $35 \mathrm{~Hz}$ is imposed on the pump is presented in Fig. 6. There, it could be observed that the peak to peak $(\Delta P)$ pressure amplitude in the cavity was 0.2 bars while 0.35 bars were measured in the inlet line.

This reference case was repeated for the frequencies of $45 \mathrm{~Hz}$, $55 \mathrm{~Hz}, 65 \mathrm{~Hz}$ and $75 \mathrm{~Hz}$, and for all three different evaporators. The results are presented in Fig. 7 where it could be observed that the actual evaporator shape did not influence significantly the peak-to-peak pressure amplitudes. Regarding the influence of pump frequency, the peak-to-peak pressure amplitude in the cavity was not affected which suggests that reflections inside the cavity tended to blur out the details of the incoming pressure waves. Moreover, at the same time, the frequency of the pressure waves inside the cavity tended to follow closely the frequency of the reciprocating pump. Peak-to-peak pressure amplitude in the inlet line showed a maximum at $55 \mathrm{~Hz}$. At this frequency, $\Delta P_{\text {line }}$ was 0.47 bar while it was 0.39 bar (20\% smaller) at $35 \mathrm{~Hz}$. The reason for this could be that at the frequency of $55 \mathrm{~Hz}$ the interaction of the wave trains with the specific geometry under consideration favored this amplification.

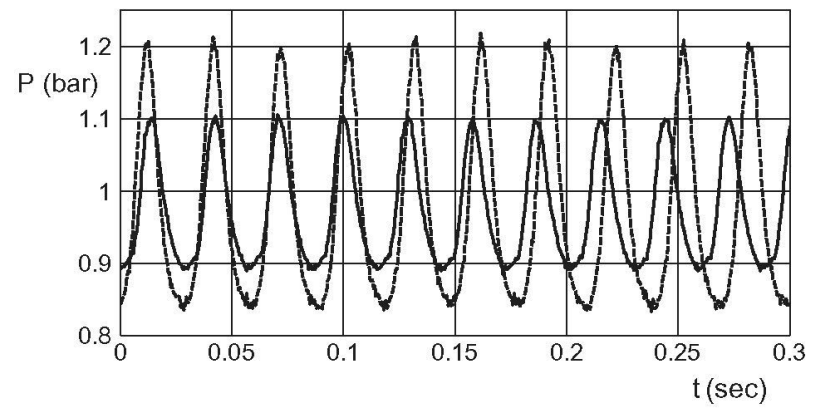

Fig. 6. Time histories of the pressure in the cavity (solid line) and in the inlet line (dashed line) in the reference case with no heat applied when the pump frequency is $35 \mathrm{~Hz}$. The evaporator is the one with the $500 \mu \mathrm{m}$ pin fins.

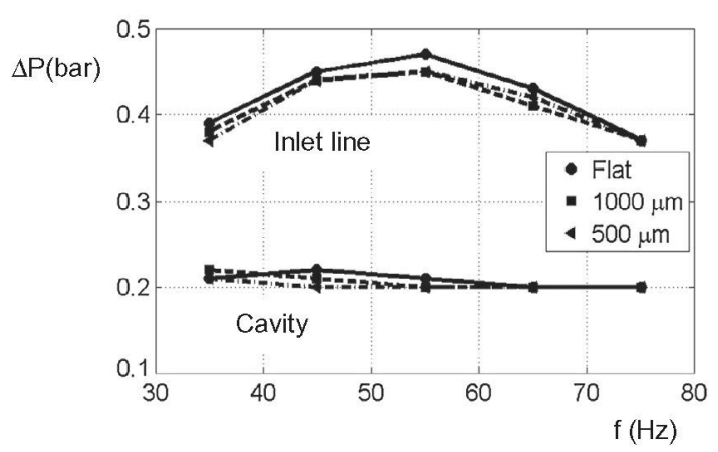

Fig. 7. Reference case with no heat applied. $\Delta P$ in the cavity and in the inlet line as a function of frequency for the three different evaporator geometries.

\subsection{Pressure attenuation in the cavity}

Once the reference case was characterized, heat was applied to the evaporator to achieve a series of stable surface temperatures, $40^{\circ} \mathrm{C}, 50^{\circ} \mathrm{C}, 60^{\circ} \mathrm{C}, 70^{\circ} \mathrm{C}$ and $80^{\circ} \mathrm{C}$ for the three different evaporators. The pump frequency was also varied between $35 \mathrm{~Hz}$ and $75 \mathrm{~Hz}$ with steps of $10 \mathrm{~Hz}$. For any given evaporator geometry, surface temperature and pump frequency, the peak-to-peak pressure amplitude in the cavity did not remain strictly constant. Instead, it showed a slightly unsteady behavior. Instead, its distribution showed a Gaussian-like behavior around the mean that will be discussed in a later section. This was due to the random spatial character of bubble formation at the evaporator surface as well as the random buoyancy driven bubble motion.

Regarding the time-averaged valued of the peak-to-peak pressure amplitude, it was found that, like in the reference case, $\Delta P$ in the cavity was not affected by the working frequency of the pump. The results of the attenuation cavity pressure factor $K_{\Delta \text { Pcav- }}$ ity defined as $\left(\Delta P / \Delta P_{\text {reference }}\right)_{\text {cavity, whe }} \Delta P_{\text {reference }}$ is taken from Fig. 7 ( 0.2 bars) are presented in Fig. 8 . There, it could be observed that the attenuation factor decreases almost linearly as a function of the evaporator surface temperature and that, if engineering applications are sought, the practical differences associated to the different evaporators are not significant. It is to be noted that the attenuation factor is in the range from 0.40 to 0.60 at $60^{\circ} \mathrm{C}$, and in the range from 0.15 to 0.18 at $80^{\circ} \mathrm{C}$ so boiling and the subsequent generation of a sizable vapor phase in the liquid effectively contrived to cause a significant attenuation of pressure waves.

However, evaporator surface temperature does not scale linearly with the input electrical power needed to keep it at the prescribed thermal level. To put it in another way, it was found that the attenuation factor does not decrease linearly with the input electrical power needed to keep the evaporator surface a prescribed temperature. For example, in the case of the $500 \mu \mathrm{m}$

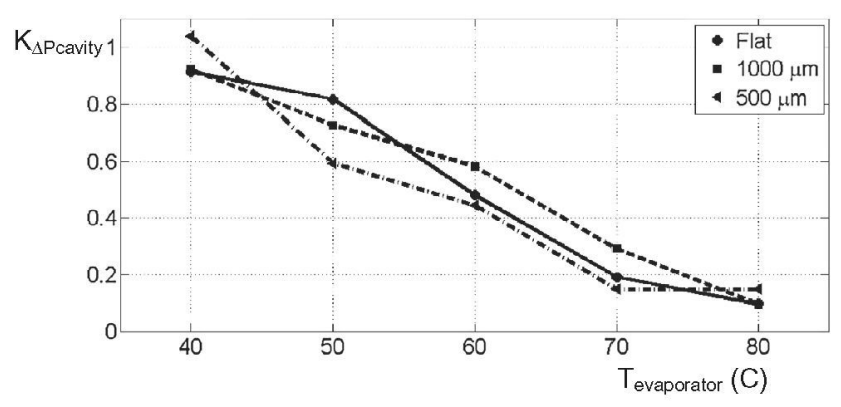

Fig. 8. Cavity pressure attenuation factor $K_{\Delta \text { Pcavity }}$ as a function of the evaporator surface temperature for the pump frequency of $35 \mathrm{~Hz}$. 
pin-fin evaporator, the input power needed to keep evaporator temperature at $40^{\circ} \mathrm{C}, 50^{\circ} \mathrm{C}, 60^{\circ} \mathrm{C}, 70^{\circ} \mathrm{C}$ and $80^{\circ} \mathrm{C}$ was $2.1 \mathrm{~W}$, $3.2 \mathrm{~W}, 5.9 \mathrm{~W}, 21.6 \mathrm{~W}$ and $30.6 \mathrm{~W}$ respectively. The large increase in power versus the monotonic increase in temperature is caused by the behavior of the heat transfer coefficient that grows sharply once boiling has started [23]. A summary of these results that relate the attenuation factor to the input electrical power is presented in Fig. 9. What is significant in these results is that an input power of $5 \mathrm{~W}$ leads to an attenuation factor of about 0.5 (reduction by a factor of 2 from the reference case); while $22 \mathrm{~W}$ (about four times as much) are needed to get the attenuation factor down by another factor of 2 . It could also be observed that further increases on the input power lead to marginal gains on the attenuation factor.

At the evaporator surface temperature of $60^{\circ} \mathrm{C}(5.9 \mathrm{~W})$ bubbling was vigorously promoted at the evaporator surface but bubbles were generated individually, they could be tracked down in the video picture and they only collapsed into each other as they moved away (upwards) from the evaporator surface, see Fig. 10 where a video snapshot is presented. At $70^{\circ} \mathrm{C}(21.6 \mathrm{~W})$ there appears to be a large gaseous structure located on the evaporator surface suggesting that boiling was so massive that vapor structures with sizes similar to the size of the evaporator itself were continuously created and convected upwards. The large size of one of these structures can be observed right on top of the evaporator in the right snapshot of Fig. 10. The associated cavity pressure time histories of these two cases, and their comparison with the reference isothermal case, are presented in Fig. 11.

As already mentioned in Section 2, fluid temperature inside the cavity was also measured. The results obtained (that showed no dependency on pump frequency) for the $500 \mu \mathrm{m}$ evaporator were $33^{\circ} \mathrm{C}, 38^{\circ} \mathrm{C}, 46^{\circ} \mathrm{C}, 54{ }^{\circ} \mathrm{C}$ and $54^{\circ} \mathrm{C}$ when the evaporator temperatures were $40^{\circ} \mathrm{C}, 50^{\circ} \mathrm{C}, 60^{\circ} \mathrm{C}, 70^{\circ} \mathrm{C}$ and $80^{\circ} \mathrm{C}$ respectively. The saturation temperature at $94 \mathrm{kPa}$ (lab atmospheric pressure) was $59.2^{\circ} \mathrm{C}$. This shows that the measured fluid temperature was consistently lower than the saturation temperature. The authors believe that reasons are twofold: (a) the thermocouple measuring fluid temperature was located at the wall opposite to the evaporator, and (b) the depth of the cavity was $20 \mathrm{~mm}$ only. This means that the spatial temperature gradients were large in the direction perpendicular to the evaporator. In particular, the evaporator temperature was high and the fluid next to it was at the saturation temperature, while $20 \mathrm{~mm}$ away the fluid was in contact with the cavity wall that was significantly lower.

The vapor void fraction in the cavity was measured indirectly out of the video recordings. To this end, the software BlobsDemo developed by ImageAnalyst [24] was used. Five different video streams were analyzed for each evaporator temperature $\left(40^{\circ} \mathrm{C}\right.$, $50^{\circ} \mathrm{C}, 60^{\circ} \mathrm{C}$, and $70^{\circ} \mathrm{C}$ ). The measured values of the bubble diameters were $0.40 \mathrm{~mm} \pm 0.08 \mathrm{~mm}, 0.62 \mathrm{~mm} \pm 0.12 \mathrm{~mm}, 1.44 \mathrm{~mm} \pm$ $0.10 \mathrm{~mm}$, and $9.53 \pm 0.50 \mathrm{~mm}$. The vapor void fractions associated

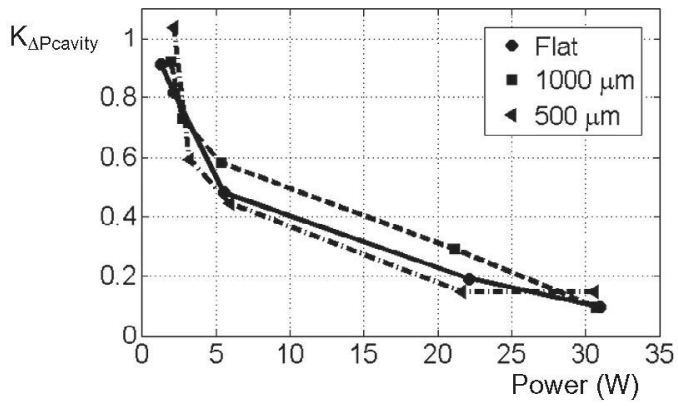

Fig. 9. Attenuation factor $K_{\Delta \text { Pcavity }}$ versus input electrical power to the cartridge heater for the pump frequency of $35 \mathrm{~Hz}$.

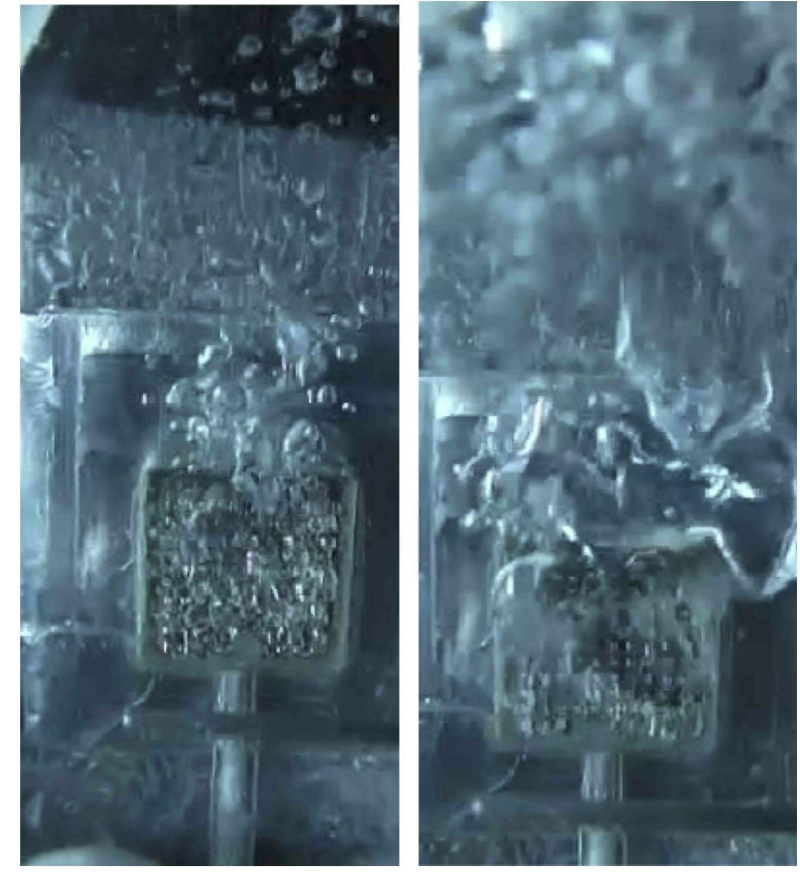

Fig. 10. Video snapshots of the pool boiling tests at a pump frequency of $35 \mathrm{~Hz}$ and with the $500 \mu \mathrm{m}$ pin-fin evaporator. Left snapshot: evaporator temperature $60^{\circ} \mathrm{C}$, input electrical power $5.9 \mathrm{~W}$, attenuation factor 0.43 . Right snapshot: evaporator temperature $70^{\circ} \mathrm{C}$, input electrical power $21.6 \mathrm{~W}$, attenuation factor 0.14 .

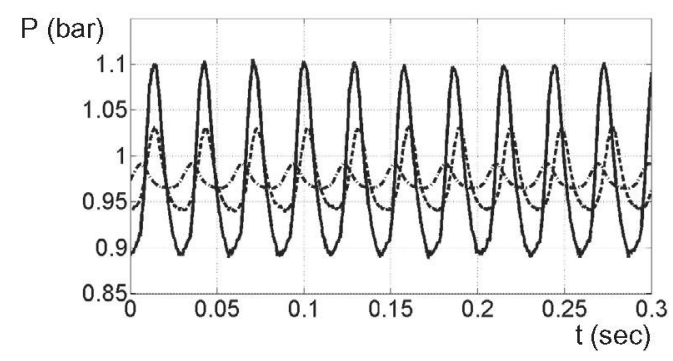

Fig. 11. Time evolution of pressure in the cavity with the $500 \mu \mathrm{m}$ pin-fin evaporator and pump running at $35 \mathrm{~Hz}$. Solid line: isothermal reference case. Dashed line: pool boiling case with evaporator temperature equal to $60^{\circ} \mathrm{C}$ (input electric power $5.9 \mathrm{~W}$ ). Dashed dotted line: pool boiling case with evaporator temperature equal to $70^{\circ} \mathrm{C}$ (input electric power $21.6 \mathrm{~W}$ ).

to the four evaporator temperatures were: $0.012 \% \pm 0.006 \%$, $0.09 \% \pm 0.02 \%, 1.24 \% \pm 0.12 \%$ and $19.9 \% \pm 1.16 \%$ respectively. It is to be noted that at $70^{\circ} \mathrm{C}$ the bubbling was so massive, see Fig. 10, that the computations made with BlobsDemo may have a qualitative (not quantitative) character only. It could be observed that, as it might be anticipated, larger vapor void fractions correspond to larger attenuation of the pressure waves in the cavity, see Figs. 8 and 9 .

The effect of the evaporator geometry on the pressure attenuation factor was found to be smaller than the influence of evaporator temperature. Table 1 shows the peak-to-peak pressure amplitude with the three different evaporators, pump running at $35 \mathrm{~Hz}$, and evaporator temperature of $40^{\circ} \mathrm{C}, 60^{\circ} \mathrm{C}$ and $70^{\circ} \mathrm{C}$.

Finally, it is also important to quantify the effect of pump frequency on the attenuation factor. In this regard, it was found that the influence of frequency was small and that the observed differences were within the measurement uncertainty of the experimental results, so no clear conclusion could be drawn. A summary of these results for the case of the $500 \mu \mathrm{m}$ pin-fin evaporator are presented in Table 2. A steady decrease on the peak-to-peak pressure 
Table 1

Peak-to-peak pressure amplitude with the three different evaporators, pump running at $35 \mathrm{~Hz}$, and evaporator temperature of $40^{\circ} \mathrm{C}, 60^{\circ} \mathrm{C}$ and $70^{\circ} \mathrm{C}$.

\begin{tabular}{llll}
\hline$T_{\text {evaporator }}\left({ }^{\circ} \mathrm{C}\right)$ & \multicolumn{4}{l}{ Evaporator geometry } \\
\cline { 2 - 4 } & $\begin{array}{l}\text { Flat } \\
\Delta P_{\text {cavity }}(\text { bar })\end{array}$ & $1000 \mu \mathrm{m}$ & $500 \mu \mathrm{m}$ \\
\hline 40 & 0.20 & 0.22 & 0.22 \\
50 & 0.18 & 0.18 & 0.15 \\
60 & 0.11 & 0.11 & 0.09 \\
70 & 0.04 & 0.04 & 0.04 \\
80 & 0.01 & 0.01 & 0.01 \\
\hline
\end{tabular}

amplitude could be observed as a function of the evaporator temperature (row wise) while not significant differences were observed when frequency was changed (column wise). Pressure measurement uncertainties were of the order of $\pm 10 \%$ and they changed from $\pm 7 \%$ at $50{ }^{\circ} \mathrm{C}$ to $\pm 11 \%$ at $60^{\circ} \mathrm{C}$.

\subsection{Pressure attenuation in the line leading to the cavity}

The situation in the line leading to the cavity was different in the sense that the attenuation factor was much smaller than in the case of the cavity. Fig. 12 shows the counterpart of Fig. 11 where it could be observed that, in this case, the attenuation factor for the two evaporator temperatures on $60^{\circ} \mathrm{C}$ and $70^{\circ} \mathrm{C}$ was 0.75 .

\subsection{Repeatability and uncertainty bands of the results}

As it has been explained before, 3 geometries, 6 temperatures (including the isothermal reference case) and 5 pump frequencies were considered. After steady temperature conditions were achieved, each test lasted for $1 \mathrm{~min}$ which means that the number of recorded cycles per test varied from 2100 to 4500 depending on the pump frequency. Regarding repeatability, each single test was repeated three times at three different days which makes a total number of tests of $3 \times 6 \times 5 \times 3=270$. The repeatability tests showed a consistent pattern both qualitatively and quantitatively. One example of this is presented in Fig. 13 where time evolution of pressure in the cavity is presented for the three different repeatability tests in the case of the $500 \mu \mathrm{m}$ pin-fin evaporator and evaporator temperatures of $60^{\circ} \mathrm{C}$ and $70^{\circ} \mathrm{C}$.

As it has been already mentioned in a previous section, the peak-to-peak pressure amplitudes in the cavity showed a slightly random behavior. To quantify the uncertainty band associated to this behavior and, also, to the three repeatability tests, a histogram was produced for each triplet of tests. Fig. 14 shows this histogram for the case of the $500 \mu \mathrm{m}$ pin-fin evaporator, evaporator temperatures of $60^{\circ} \mathrm{C}$ and pump frequency of $35 \mathrm{~Hz}$ (pressure profiles shown in Fig. 13 with the larger amplitude). To generate the histogram, 100 cycles were selected at random from the three repeatability tests. As it could be observed in Fig. 14, the histogram

Table 2

Peak-to-peak pressure amplitude for the case of the $500 \mu \mathrm{m}$ pin-fin evaporator as a function of the evaporator temperature and frequency of the reciprocating pump.

\begin{tabular}{|c|c|c|c|c|}
\hline \multirow[t]{2}{*}{$T_{\text {evaporator }}\left({ }^{\circ} \mathrm{C}\right)$} & \multicolumn{3}{|c|}{ Pump frequency } & \multirow[t]{2}{*}{ Mean $\Delta P_{\text {cavity }}$ (bar) } \\
\hline & \multicolumn{3}{|c|}{$\Delta P_{\text {cavity }}$ (bar) } & \\
\hline 40 & 0.22 & 0.22 & 0.20 & $0.21 \pm 10 \%$ \\
\hline 50 & 0.15 & 0.13 & 0.13 & $0.14 \pm 7 \%$ \\
\hline 60 & 0.09 & 0.08 & 0.09 & $0.09 \pm 11 \%$ \\
\hline 70 & 0.04 & 0.05 & 0.05 & $0.05 \pm 10 \%$ \\
\hline 80 & 0.01 & 0.01 & 0.01 & 0.01 \\
\hline
\end{tabular}

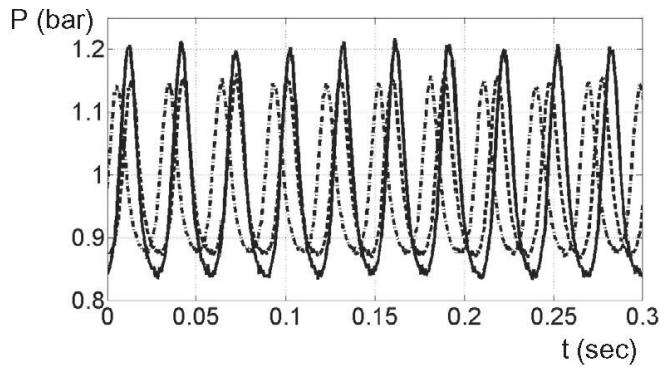

Fig. 12. Counterpart of Fig. 11 for the pressure history in the line leading to the cavity. The attenuation factor is 0.75 .

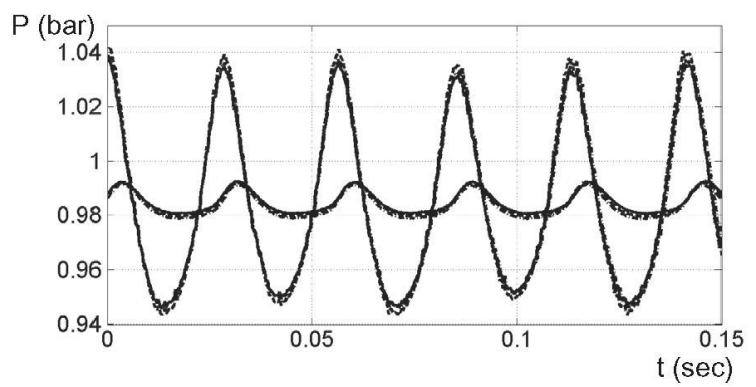

Fig. 13. Time evolution of pressure in the cavity is presented for the three different repeatability tests (solid, dashed, and dashed-dotted lines respectively) in the case of the $500 \mu \mathrm{m}$ pin-fin evaporator and evaporator temperatures of $60^{\circ} \mathrm{C}$ (larger amplitude pressure oscillations) and $70^{\circ} \mathrm{C}$ (smaller amplitude pressure oscillations).

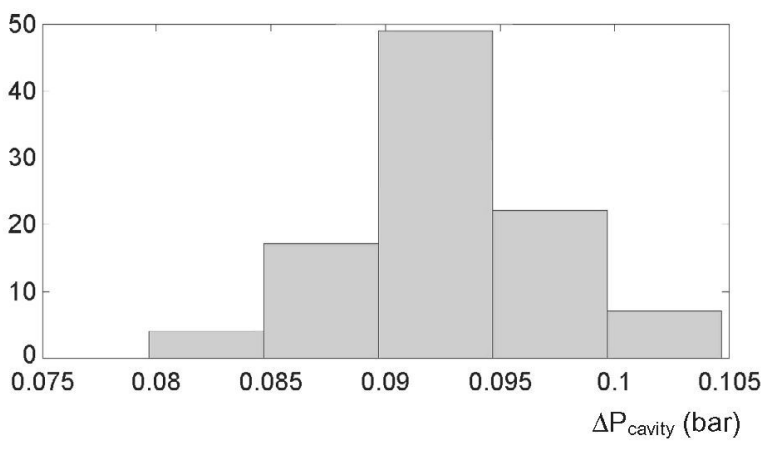

Fig. 14. Histogram of the peak-to-peak pressure amplitudes in the cavity. A 100 cycles were selected at random from the three repeatability cases. Conditions were: $500 \mu \mathrm{m}$ pin-fin evaporator, surface temperature $60^{\circ} \mathrm{C}$ and pump frequency $35 \mathrm{~Hz}$. The mean of the histogram was $0.0927 \mathrm{bar}$ and the standard deviation 0.0049 bar.

showed a Gaussian-like behavior with a mean of 0.0927 bar and a standard deviation of 0.0049 bar.

The issue of the measurements uncertainty bands is also relevant for the discussion of the influence of evaporator geometry on the observed results. The pressure attenuation factor in Fig. 9 was presented, for the sake of clarity, without uncertainty bands. Now, the counterpart of Fig. 9 is presented in Fig. 15. In this new figure, it is observed how the uncertainty bands associated to the three different evaporator configurations overlap each other so it is not possible to draw a conclusion regarding the influence of surface micro-structure. If such influence exists, its extent is smaller than the size of the uncertainty bands. The only discernible effect is that the uncertainty band associated to the $500 \mu \mathrm{m}$ pin-fin evaporator is significantly broader than in the other two configurations. The reason could be associated to the local effect of intense generation of bubbles in this configuration; at the larger scale, the global 


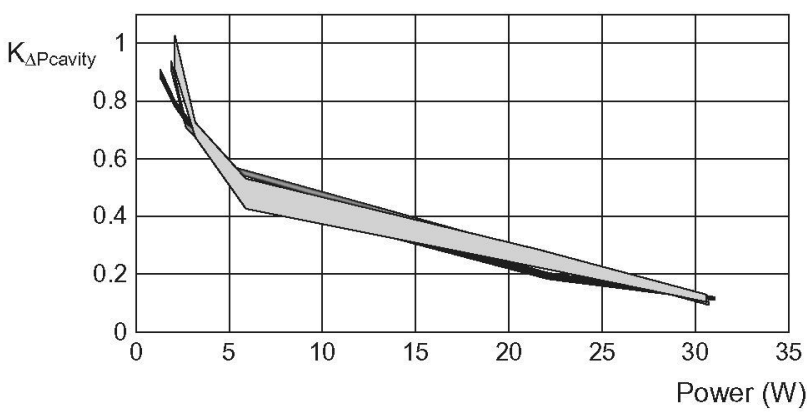

Fig. 15. Counterpart of Fig. 9 including uncertainty bands. Flat evaporator: black band, $1000 \mu \mathrm{m}$ pin-fin evaporator: dark-grey band, $500 \mu \mathrm{m}$ pin-fin evaporator: light-grey band.

effect on the pressure attenuation might not depend of the actual surface geometry but the intense bubbling in the $500 \mu \mathrm{m}$ pin-fin evaporator might cause larger randomness which, in turn, may lead to a broader uncertainty band. In any case, even though the type of surface could be important in boiling inception, this does not seem to be significant in the present study. This could be a subject to be addressed in more detail in a future work.

Another aspect that needs further discussion is that results presented in Fig. 9 compare the pressure attenuation factor versus the input electrical power. However, a fraction of the input power is dissipated outside the cavity via natural convection losses and does not find its way into the evaporator. To estimate these losses, additional thermocouples were set at different locations in the experimental setup (outside of the Styrofoam insulation layers and on the outer surface of the cavity). Then, these measurements were used to compute natural convection losses and to provide an estimate of the actual thermal power going into the evaporator. The relation between the input electrical power supplied to the cartridge and the thermal power in the evaporator is presented in Fig. 16 where the results obtained in 75 cases involving repeatability tests for the different evaporators at several pump frequencies are presented. The solid black line in Fig. 15 shows the ideal situation in which no losses occur (input electric power equals the thermal power). The actual tests results are presented as discrete shaded dots (these results tend to be rather close because of the reasonably good outcome of repeatability tests). Additionally a first order fitting line (represented as a dash dotted line) has been drawn for comparison purposes. These losses, depending on the input power are in the range from $1 \mathrm{~W}$ to $3 \mathrm{~W}$. It is because of this comparatively small value and the fact that, as observed in Fig. 16, electrical and thermal power correlate reasonably well, that it has been decided to present the results of the pressure attenuation factor in the cavity as a function of the input electrical power.

\section{Flow boiling results}

In this case, the valve leading to the secondary circuit was closed and all the flow passing through the pump was diverted into

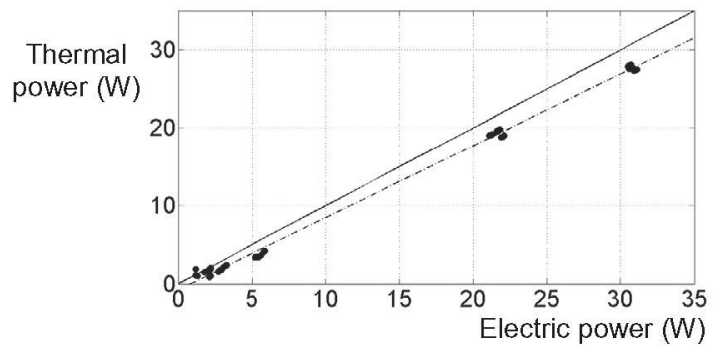

Fig. 16. Computed estimate of the actual thermal power going into the evaporator as a function of the electrical power supplied to the cartridge. the cavity. Tests were carried out for five pump frequencies $(35 \mathrm{~Hz}$, $45 \mathrm{~Hz}, 55 \mathrm{~Hz}, 65 \mathrm{~Hz}, 65 \mathrm{~Hz}$ ), three evaporator geometries similar to those described in the previous section (flat, $1000 \mu \mathrm{m}$ pin-fin, and $500 \mu \mathrm{m}$ pin-fin geometries), and five evaporator temperatures $\left(40^{\circ} \mathrm{C}, 50^{\circ} \mathrm{C}, 60^{\circ} \mathrm{C}, 70^{\circ} \mathrm{C}\right.$, and $\left.80^{\circ} \mathrm{C}\right)$. Measured flow rates were in the range from $41 \mathrm{~cm}^{3} / \mathrm{min}$ to $229 \mathrm{~cm}^{3} / \mathrm{min}$. The Reynolds number in the line out of the reciprocating pump (based on the line diameter) was in the range from 263 up to 1538 . This means that the flow was laminar in this section of the circuit and that pump frequency, pressure wave amplitude and mass flow rate were coupled together as in the theoretical solution of the unsteady Poiseuille flow [22]. In practice, this meant that a different flow rate was generated for each different pump frequency. Furthermore, this flow rate was affected by two additional effects. The first one was that the finite-length line discharged into the cavity as opposed to the ideal unsteady Poiseuille flow in which flow derivatives along the line axis are supposed to be zero. The second one was the effect of bubble generation which significantly altered the character of the flow in the cavity because of the generation of large turbulent instabilities with sizes of the order of the cavity size itself. These two effects contrived to increase the global pressure loss and, therefore, to limit the flow rate. To make this effect apparent, Table 3 shows the measured flow rates as a function of the evaporator temperatures for the lowest $(35 \mathrm{~Hz})$ and highest ( $75 \mathrm{~Hz}$ ) pump frequencies and their comparison with the isothermal reference case for the $500 \mu \mathrm{m}$ pin-fin evaporator configuration. It could be observed that at the highest evaporator temperature $\left(80^{\circ} \mathrm{C}\right)$, the flow rates are smaller than their associated isothermal reference case by a factor of nearly 3 .

To have a qualitative idea of the character of the flow in the cavity, it was illustrative to compute the Reynolds number in the isothermal single-phase case. This Reynolds number was defined accounting for the measured flow rate (to yield the characteristic velocity) and using the hydraulic diameter of the cavity (25.45 $\mathrm{mm}$ ) as the characteristic length (the hydraulic diameter was conventionally defined as four times the cross section area divided by the perimeter). At the highest frequency of $75 \mathrm{~Hz}$ and lowest flow rate of $121 \mathrm{~cm}^{3} / \mathrm{min}$, the Reynolds number was 187 (HEC density and dynamics viscosity at $20^{\circ} \mathrm{C}$ are $1482 \mathrm{~kg} / \mathrm{m}^{3}$ and $5.82 \times 10^{-4} \mathrm{~kg} / \mathrm{ms}$. A full datasheet can be found in Ref. [21]).

Now, for the sake of brevity, only the most relevant results of the experimental tests are presented in Fig. 17. In particular, the pressure attenuation factor in the cavity is plotted versus the input electric power for the $500 \mu \mathrm{m}$ pin-fin evaporator at the different pump frequencies in the range from $35 \mathrm{~Hz}$ to $75 \mathrm{~Hz}$. Three distinct regions could be observed in Fig. 17. There is, first, a sharp drop in the attenuation factor up to about $5 \mathrm{~W}$ of electrical power that corresponds to a evaporator temperature of $60^{\circ} \mathrm{C}$. The attenuation factor at $35 \mathrm{~Hz}$ was about 0.2 that should be compared with its counterpart attenuation factor, of the order of 0.4 , in the pool boiling case, see Fig. 9. This suggests that the proposed method to damp pressure waves is more efficient in flow boiling than in pool boiling situations. Second, there is a plateau-like behavior in the range from about $5 \mathrm{~W}$ to about $22 \mathrm{~W}$, that correspond to the evaporator temperature range of $60-70^{\circ} \mathrm{C}$. In this range, it could be observed that attenuation is larger (smaller attenuation factor) at the lowest frequencies. Finally, at the maximum power of about $32 \mathrm{~W}$ that corresponds to an evaporator temperature of $80^{\circ} \mathrm{C}$, boiling is so massive that results for the different frequencies tend to collapse suggesting that the flow is dominated by instabilities.

This type of behavior has also been observed for the other two evaporators (flat and $1000 \mu \mathrm{m}$ pin-fin). These results, as well as the results of the repeatability tests, histogram of measurements and uncertainty bands, are not presented here for the sake of brevity and because they do not show significant departures from the trends already discussed. 
Table 3

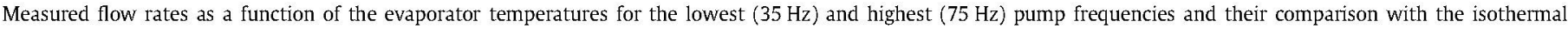
reference case for the $500 \mu \mathrm{m}$ pin-fin evaporator configuration.

\begin{tabular}{|c|c|c|c|c|c|}
\hline \multicolumn{3}{|l|}{$35 \mathrm{~Hz}$} & \multicolumn{3}{|l|}{$75 \mathrm{~Hz}$} \\
\hline Qlow isothermal $\left(\mathrm{cm}^{3} / \mathrm{min}\right)$ & $T_{\text {evap }}\left({ }^{\circ} \mathrm{C}\right)$ & $\mathrm{Q}_{\text {flow }}\left(\mathrm{cm}^{3} / \mathrm{min}\right)$ & Qflow isothermal $\left(\mathrm{cm}^{3} / \mathrm{min}\right)$ & $T_{\text {evap }}\left({ }^{\circ} \mathrm{C}\right)$ & $Q_{\text {flow }}\left(\mathrm{cm}^{3} / \mathrm{min}\right)$ \\
\hline \multirow[t]{5}{*}{228} & 40 & 229 & 121 & 40 & 116 \\
\hline & 50 & 179 & & 50 & 90 \\
\hline & 60 & 142 & & 60 & 71 \\
\hline & 70 & 112 & & 70 & 56 \\
\hline & 80 & 88 & & 80 & 44 \\
\hline
\end{tabular}

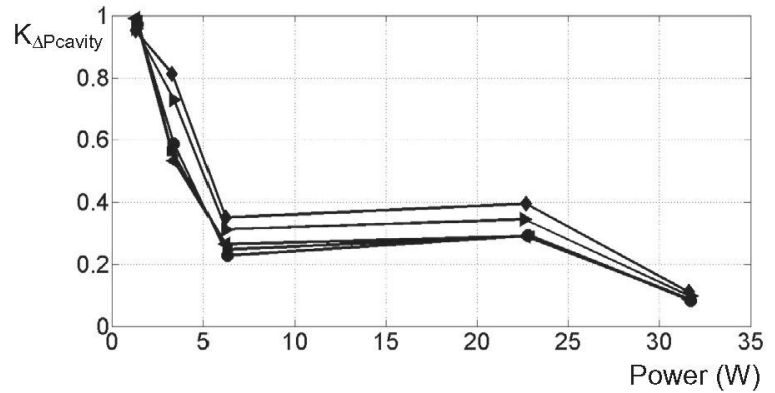

Fig. 17. Pressure attenuation factor in the cavity versus input electrical power for the $500 \mu \mathrm{m}$ pin-fin evaporator at different pump frequencies. Shaded circle: $35 \mathrm{~Hz}$, square: $45 \mathrm{~Hz}$, left-looking triangle: $55 \mathrm{~Hz}$, right-looking triangle: $65 \mathrm{~Hz}$, diamond: $75 \mathrm{~Hz}$.

The vapor void fraction in the cavity was, again, measured indirectly from the video recordings. Five different video streams were also analyzed for each evaporator temperature $\left(40^{\circ} \mathrm{C}, 50^{\circ} \mathrm{C}, 60^{\circ} \mathrm{C}\right.$, and $70^{\circ} \mathrm{C}$ ). The measured bubble diameters were $0.36 \mathrm{~mm} \pm 0.07$ $\mathrm{mm}, \quad 0.56 \mathrm{~mm} \pm 0.09 \mathrm{~mm}, \quad 1.31 \mathrm{~mm} \pm 0.09 \mathrm{~mm}$, and $8.58 \pm 0.42$ $\mathrm{mm}$. The vapor void fractions associated to the four evaporator temperatures were: $0.012 \% \pm 0.006 \%, 0.08 \% \pm 0.02 \%, 1.12 \% \pm 0.10 \%$ and $17.60 \% \pm 1.03 \%$ respectively. It is to be noted that average bubble diameters and void fractions in the flow boiling case were smaller than in the pool boiling situation.

\section{Conclusions}

A method to attenuate pressure waves in cavities consisting of creating a controlled boiling regime has been studied experimentally. The main conclusions of the study are as follows:

- Low frequency pressure waves in a cavity $(35-75 \mathrm{~Hz}$ ) could be attenuated effectively via boiling both in the cases of pool and flow boiling. However, it seems that the proposed method is more efficient in the case of flow boiling. Depending on the specific details of the parameters governing the problem, peak-topeak pressure amplitudes could be reduced by a factor of 10 as compared to the cases when no heat is applied.

- In the case of pool boiling, peak-to-peak pressure wave amplitudes showed a monotonic decrease along with the input electrical power. However, the rate of decrease was dependent on the power itself. In particular, the peak-to-peak pressure wave amplitude could be reduced effectively up to a point characterized by some specific input electrical power to the evaporator. However, beyond that point, diminishing returns were observed in the sense that, for example, power had to be multiplied by a factor of 4 to halve the peak-to-peak pressure wave amplitude. Also, both the quantitative and qualitative behavior of the pool boiling cases were rather insensitive with regard to the actual evaporator geometry and frequency of the incoming pressure waves.
- In the case of flow boiling, peak-to-peak pressure wave amplitude also decreased along with the input electrical power supplied to the evaporator. However, as opposed to the pool boiling case, a plateau-like region was observed for a rather wide span of intermediate input powers. Also, although the results were not measurably sensitive to the actual evaporator geometry, they indeed appeared to be influenced by the pressure wave frequency. In particular better attenuation factors (smaller peak-to-peak pressure wave amplitudes) were obtained in the cases with the lower frequencies (around $35 \mathrm{~Hz}$ )

- The massive instabilities created in the cavity via flow boiling caused significant flow pressure losses leading to reductions in the actual flow rate of the order of $70 \%$ as compared with the cases when no heat was applied to the evaporator.

- Regarding the actual applicability of the proposed method to practical engineering situations it seems that two criteria could be used to maximize the ratio of gains versus costs. These two criteria are: (a) a flat evaporator would suffice since there is no evidence that a far complex (and expensive) geometry provides better gains, and (b) power should be provided just to reach the level when massive boiling starts (when the evaporator reaches the boiling temperature) but not beyond because, then, gains tend to follow a law of diminishing returns. In practical terms, the use of a flat evaporator combined with an input electrical power of about $5 \mathrm{~W}$ allowed, in the cavity used for the experiments, for a pressure wave attenuation factor of 0.4 in the case of pool boiling, and a pressure attenuation factor of 0.2 in the case of flow boiling.

\section{Acknowledgements}

J. Rojas-Herrera was funded by the MIT-Spain Program under contract 2013-03-07. A. Velazquez and J.R. Arias were funded by the Spanish Ministry of Economy and Competitiveness (Ministerio de Economia y Competitividad) under research contract DPI201345207. The authors gratefully acknowledge these two sources of support. Also, the authors want to express their thanks to two anonymous Reviewers for their comments on the manuscript.

\section{References}

[1] A. Mallock, The damping of sound in frothy liquids, Proc. Roy. Soc. Ser. A 84 (1910) 391.

[2] E.l. Carstensen, L.L. Foldy, Propagation of sound through a liquid containing bubbles, J. Acoust. Soc. Am. 19 (1947) 481-501.

[3] L. Van Wijngaarden, On equations of motion for mixtures of liquid and gas bubbles, J. Fluid Mech. 33 (1968) 465-474.

[4] R.E. Caflisch, M.J. Miksis, G.C. Papanicolaou, L. Ting, Effective equations for wave propagation in bubbly fluids, J. Fluid Mech. 153 (1985) 259-273.

[5] K.W. Commander, A. Prosperetti, Linear pressure waves in bubbly liquids: comparison between theory and experiments, J. Acoust. Soc. Am. 85 (1989) $732-746$.

[6] E. Silberman, Sound velocity and attenuation in bubbly mixtures measured in standing wave tubes, J. Acoust. Soc. Am. 29 (1957) 925-933. 
[7] A. Prosperetti, Bubble phenomena in sound fields, Ultrasonics 22 (1984) 6977.

[8] L. D'Agostino, C.E. Brennen, Acoustical absorption and scattering cross sections of spherical bubble clouds, J. Acoust. Soc. Am. 84 (1988) 2126-2134.

[9] S. Nomura, M. Nakagawa, Analysis of ultrasonic field attenuated by oscillating cavitation bubbles, Acoust. Sci. Technol. 22 (2001) 283-291.

[10] V.E. Dontsov, V.E. Nakoryakov, Attenuation of the pressure wave in a liquidgas medium with stratified structure. XIII Session of the Russian Acoustical Society, Moscow, August 2003.

[11] R. Raju, S. Singh, C.-T. Hsiao, G. Chahine, Study of a strong pressure wave propagation in a two-phase bubbly mixture, in: Proceedings of the ASME 2010 International Mechanical Engineering Congress \& Exposition IMECE2010, November (2010) Vancouver, British Columbia, Canada.

[12] R.M. Fand, The influence of acoustical vibrations on heat transfer by natural convection from a horizontal cylinder to water, J. Heat Transfer 87 (1965) 309310.

[13] K.W. Li, J.D. Parker, Acoustical effects on free convective heat transfer from a horizontal wire, J. Heat Transfer 89 (1967) 277-278.

[14] K.A. Park, A.E. Bergles, Ultrasonic enhancement of saturated and subcooled pool boiling, Int. J. Heat Mass Transf. 31 (1998) 664-667.

[15] Y. lida, K. Tsutsui, Effects of ultrasonic waves on natural convection, nucleate boiling and film boiling heat transfer from a wire to a saturated liquid, Exp. Thermal Fluid Sci. 5 (1998) 108-115.

[16] H. Yamashiro, H. Takamatsu, H. Honda, Effects of ultrasonic vibration on transient boiling heat transfer during rapid quenching of a thin wire in water ASME J. Heat Transfer 120 (1998) 282-286.
[17] Ho-Young Kim, Yi Gu Kim, Byung Ha Kang, Enhancement of natural convection and pool boiling heat transfer via ultrasonic vibrations, Int. J. Heat Mass Transf. 47 (2004) 2831-2840.

[18] F. Baffigi, C. Bartoli, Influence of the ultrasounds on the heat transfer in single phase free convection and in saturated pool boiling, Exp. Thermal Fluid Sci. 36 (2012) 12-21.

[19] M. Futakawa, H. Kogawa, S. Hasegawa, T. Naoe, M. Id, K. Haga, T. Wakui, N. Tanaka, Y. Matsumoto, Y. Ikeda, Mitioation technologies for damage induced by pressure waves in high-power mercury spallation neutron sources (II) bubbling effect to reduce pressure wave, J. Nucl. Sci. Technol. 45 (2008) 1041 1048.

[20] P. Tuma, L. Tousignant, Reducing emissions of heat transfer fluids, SEM Technical Symposium: Innovation in Semiconductor Manufacturing, SEMICON West 2001, San Francisco, USA.

[21] 3M Specialty Materials, 3M Center, Building 223-65-04, St. Paul, MN 55144$1000<w w w .3 m . c o m / f l u i d s>$.

[22] A. Velazquez, J.R. Arias, B. Mendez, Laminar heat transfer enhancement downstream of a backward facing step by using a pulsating flow, Int. J. Heat Mass Transf. 51 (2008) 2075-2089.

[23] F.P. Incropera, D.P. DeWitt, Introduction to Heat Transfer, John Wiley \& Sons, NJ, 2001.

[24] ImageAnalyst, BlobsDemo: Image Segmentation Tutorial, 2009. <http:/ www.mathworks.com/matlabcentral/fileexchange/25157-imagesegmentation-tutorial-blobsdemo-/content/BlobsDemo.m>. 